\title{
Studi Populasi Serangga Sebagai Upaya Konservasi Biodiversitas Sungai Oyo, di Desa Wisata Bleberan Gunung Kidul
}

\author{
(Study of Insects Population As An Effort to Biodiversity Conservation in the Oyo \\ River, At the Ecotourism Village of Bleberan Gunung Kidul)
}

\author{
Eka Sulistiyowati*) \\ *) Fakultas Sains dan Teknologi, UIN Sunan Kalijaga, Yogyakarta \\ Email: ekasulis@gmail.com
}

\begin{abstract}
Bleberan Village has ecotourism potential in terms of insects biodiversity. Moreover, this village has some beautiful tourism objects, such as Sri Gethuk waterfall and Rancang Kencono cave. In the other hand, biodiversity in this village is yet to be explored, hence this research aims at studying insects biodiversity, especially of three orders: Orthoptera, Lepidoptera and Odonata. The final objective of this reseach is to provide information for studying and conserving biodiversity in this ecotourism region. The observation was conducted in 10 stations in both Kedung Poh (1st location) and Oyo River (2nd location ). Several ecological parameters were calculated such as density, diversity index, and distribution. In addition, enviromental parameters were also measured, i.e temperature, humidity, and light intesity. This research found 17 species of each order, with the highest number of individuals was observed in the member of Orthoptera, especially withPhlaeoba fumosa; 381 individuals (1st location 1) and 445 individuals (2nd location). In the order of Lepidoptera, species Catopsilia pomonahad the highest number of individuals, there were 31 and 46 individuals in 1st location and 2nd location, respectively. The latter is Odonata, had Orthetrum sabinawhich dominated the number with 252 individuals in 1st location and 188 individuals in 2 nd location. This research also revealed that diversity index was varied between 0.79 and 0.99 , with all orders were distributed in a clumped pattern. All the environmental factors had been observed and did not show any abnormality, therefore insects couldbe alive normally.
\end{abstract}

Keywords : Biodiversity,Insects, Orthoptera, Lepidoptera, Odonata, Bleberan, The Oyo River

\section{Pendahuluan}

Potensi ekosistem daerah aliran sungai di berbagai wilayah umumnya sangat besar. Di Daerah Istimewa Yogyakarta (DIY), ekosistem airnya secara geografis dikelompokkan dalam tiga Daerah Aliran Sungai (DAS) utama yaitu DAS Progo, DAS Opak, dan DAS Oyo (Balai Besar Wilayah Sungai Serayu Opak, 2012). Ketiga DAS ini merupakan sumber utama air di DIY yang digunakan untuk berbagai keperluan seperti irigasi, mandi, mencuci, dan rekreasi.

Sungai Oyo adalah salah satu sungai bagian dari DAS Oyoyang memiliki potensi ekonomi dan ekologi sebagai kawasan konservasi untuk perlindungan biodiversitas.Sungai Oyo memiliki keunikan dari segi geomorfologi dan ekologi, dimana sungai ini membelah kawasan karst Gunung Kidul pada formasi Wonosari (Trisnawati, 2009). Selain itu, Sungai Oyosebagai bagian utama DAS Oyo yang membentang sepanjang $35 \mathrm{~km}$ dari Kawasan Hutan Bunder di daerah Gading Gunung Kidul merupakan sungai yang unik yang terdiri atas sungai permukaan tanah dan sungai bawah tanah.DAS Oyo sendiri memiliki luas 75,473.20 hektar (Balai Pengelolaan Daerah Aliran Sungai Serayu Opak Progo, 2009).

Keunikan DAS Oyo telah lama dikelola dalam konsep ekowisata. Pemerintah Kabupaten Gunung Kidul mengelola kawasan desa-desa di DAS Oyo dalam bentuk kawasan ekowisata dan desa wisata. Sampai dengan tahun 2014, ada tiga desa wisata di DAS Oyo yaitu Desa Jelok, Desa Bobung, dan Desa Bleberan (Gunung Kidul Online, 2013). 
Potensi wisata dari desa-desa tersebut sangat beragam, mulai dari wisata geologi dan minat khusus seperti Goa Rancang Kencono dan Air Terjun Sri Gethuk di Desa Bleberan, sampai wisata hutan dan geomorfologi di wilayah Patuk (Gunung Kidul Online, 2013; Pemkab Gunung Kidul, n.d).

Potensi ekowisata yang besar di DAS Oyo tentu perlu diimbangi dengan kemampuan untuk melakukan konservasi biota yang ada di dalamnya. Langkah awal yang diperlukan dalam konsep konservasi adalah studi mengenai populasi flora dan fauna yang ada didalamnya. Dalam konsep ekowisata studi awal mengenai sistem ekologi dan biodiversitas merupakan langkah penting untuk menentukan biodiversity health (WWF Indonesia, 2009). Langkah awal inilah yang akan dilakukan dalam penelitian ini, yaitu melakukan studi populasi serangga sebagai bagian dari pemetaan di kawasan ekowisata DAS Oyo, khususnya di segmen Desa Wisata Bleberan. Hal ini karena Desa Wisata Bleberan memiliki potensi ekologi dan natural landscape yang unik dengan adanya Goa Rancang Kencono, Air Terjun Sri Gethuk, dan hamparan hutan jati dan pinus.

Pemetaan biodiversitas pada penelitian ini akan difokuskan pada pemetaan serangga, karena jenis biota ini yang paling beragam. Lebih dari separuh (64\% atau sekitar 950.000 spesies) fauna yang ada di bumi termasuk dalam golongan serangga. Keragaman spesies yang sangat besar dari kelompok ini membuat serangga memegang peranan yang sangat banyak dalam ekosistemnya, baik sebagai herbivor, predator parasitis, dekomposer, polinator, dan sebagainya (Borror et al. 1992).

Daerah Karst Gunung Sewu yang membentang dari Gunung Kidul sampai Pacitan memiliki potensi keragaman biologi yang sangat banyak. Namun, penelitian mengenai biodiversitas di Gunung Kidul masih terbatas. Lala et al. (2003) mengkaji keragaman serangga Ordo Orthoptera di wilayah Tanjung Sari, dihubungkan dengan preferensi pakan burung Lanius schach. Sementara itu keragaman Ordo Odonata Karst Gunung Sewu di Pracimantoro sangat tinggi, yaitu 5 family dan 18 species capung (Rohman, 2012). Dari beberapa penelitian tersebut, belum ada kajian khusus mengenai keragaman serangga di Sungai Oyo.
Diharapkan penelitian ini dapat menutup gap tersebut.

Dengan mempertimbangkan bahwa biodiversity health memiliki peran penting dalam upaya awal pengembangan ekowisata, maka penelitian ini akan mengungkapkan mengenai potensi keragaman serangga di Sungai Oyo Segmen Desa Wisata Bleberan. Penelitian ini difokuskan untuk melihat keragaman serangga dari tiga ordo yaitu Odonata, Lepidoptera dan Orthoptera. Ketiga ordo ini merupakan ordo dengan biodiversitas paling besar, sehingga dapat memberikan gambaran tentang biodiversity helath di lokasi Desa Wisata Bleberan.

\section{Metode penelitian}

Di dalam penelitian ini akan dilakukan beberapa langkah yaitu studi pendahuluan untuk penempatan lokasi sampling, pengambilan sampel dan identifikasi sampel. Untuk memberikan batasan pada penelitian ini, sampling hanya dilakukan di tepi sungai, yaitu pada segmen Sungai Kedung Poh (sebagai anak sungai dari Sungai Oyo yang masuk ke Sri Gethuk) dan segmen Sungai Oyo dekat dengan Jembatan Oyo, dengan 10 titik Sungai Oyo sendiri merupakan bagian dari Daerah Aliran Sungai (DAS) Oyo.

Titik pengamatan terletak pada transek dengan jarak antar masing-masing titik $10 \mathrm{~m}$. Transek dibentangkan di bantaran sungai secara membujur mengikuti arah aliran air. Pada tiaptiap 10 meter dibuat sebuah titik dan dilakukan pengamatan di titik tersebut (Van Swaay et al., 2012). Masing-masing titik di amati selama 5 jam, sehingga jumlah jam pengamatan di Lokasi 1 adalah 50 jam, dan di lokasi 2 juga selama 50 jam.

Pengambilan sampel serangga dilakukan dengan menggunakan tiga teknik, yaitu: Transect Walk untuk eksplorasi awal mengenai jenis-jenis serangga yang ditemukan, dan metode penghitungan point count untuk mengestimasi jumlah individu dalam populasinya. Identifikasi sampel dilakukan dengan cara melihat karakteristik morfologi dan merujuk kepada buku-buku biologi serangga seperti Gillot (2005) dan Borror et al. (1992).

Ada beberapa parameter yang menjadi bagian dari studi populasi serangga ini, yaitu 
1) Kelimpahan didefinisikan sebagai jumlah individu yang ditemukan (Restu, 2002).

$$
\mathrm{N}=\sum_{i=1}^{\mathrm{S}} \mathrm{N}_{i}
$$

Dimana $\mathrm{N}$ adalah jumlah individu spesies ke-i.

2) Kerapatan dihitung dengan membagi jumlah individu dengan luas area penelitian.(Krebs, 1978)

$$
D_{i}=\frac{n_{i}}{A}
$$

Dimana

Di : kerapatan individu spesies ke-i, ni:jumlah individu spesies ke-i

Tabel 1. Nilai Tolak Ukur Indeks Keragaman

\begin{tabular}{cl}
\hline Indeks & Keterangan \\
\hline $\mathrm{H}^{\prime}<$ & Keanekaragaman rendah, \\
1,0 & miskin, \\
& produktivitas sangat rendah \\
& sebagai \\
& indikasi adanya \\
& tekanan yang berat \\
& danekosistem tidak stabil \\
\hline $1,0<$ & Keanekaragaman sedang, \\
$\mathrm{H}^{\prime}<$ & produktivitascukup, \\
3,2 & kondisiekosistem \\
& cukupseimbang, \\
& tekanan ekologis sedang \\
\hline $\mathrm{H}^{\prime}>$ & Keanekaragaman tinggi, \\
3,2 & Stabilitasekosistem mantap, \\
& produktivitas tinggi. \\
\hline
\end{tabular}

(Restu, 2002)

4) Distribusi dihitung dengan indeks distribusi (sebaran) Morishita menurut Krebs (19789) yaitu:

$I \delta=\frac{n i \sum(x i(x i-1)}{N(N-1)}$

Dengan:
A: luas area kajian $\left(\mathrm{m}^{2}\right)$

3) Indeks keragaman dihitung dengan rumus (Krebs, 1978):

$$
H^{\prime}=-\sum_{i=1}^{s}\left(p_{i}\right)\left(\log _{2} p_{i}\right)
$$

dimana

$\mathrm{H}^{\prime}$ : indeks keragaman Shannon-Wiener

S: jumlah spesies

$\mathrm{Pi}$ : proporsi jumlah individu jenis ke-i dengan individu total

Indeks keragaman tersebut mencerminkan kondisi ekologis sebagai berikut:

I $\delta$ : Indeks Sebaran Morishita

$\mathrm{Ni}$ : Jumlah satuan pengambilan contoh $\mathrm{N}=$ jumlah total individu

$\mathrm{Xi}=\mathrm{Jumlah}$ individu spesies pada pengambilan contoh ke-i

Jika

I $\delta>1$ : pola sebaran bersifat mengelompok

I $\delta=1$ : pola sebaran bersifat acak

I $\delta<1$ : pola sebaran bersifat seragam

\section{Hasil dan pembahasan}

Penelitian mengenai biodiversitas serangga telah dilakukan di tepi Sungai Oyo di Segmen Desa Bleleran dengan mengambil dua lokasi yaitu, lokasi 1 di belik Kedung Poh dan lokasi 2 di Sungai Oyo yang mengalir ke arah Sri Gethuk. Hasil penelitian menunjukkan bahwa kedua lokasi tersebut memiliki keragaman spesies yang cukup baik, sehingga menjadi modal potensi wisata biodiversitas dan ekoturisme. Tabel 2 menunjukkan jumlah spesies yang ditemukan dan jumlah individu dari ordo-ordo yang diamati di dua lokasi penelitian, serta deskripsi lokasi penelitian.

\begin{tabular}{|c|c|c|}
\hline \multirow{2}{*}{\multicolumn{3}{|c|}{$\begin{array}{r}\text { Pengamatan } \\
\text { Jumlah spesies }\end{array}$}} \\
\hline & & \\
\hline - Ordo Orthoptera & 16 & 15 \\
\hline - Ordo Lepidoptera & 14 & 17 \\
\hline - $\quad$ Ordo Odonata & 17 & 14 \\
\hline
\end{tabular}

Tabel 2. Jumlah Spesies, Jumlah Individu, dan Deskripsi Lokasi Hasil Pengamatan dari Kedung Poh (Lokasi 1) dan Sungai Oyo (Lokasi 2) 
Jurnal Biologi Universitas Andalas (J. Bio. UA.)

4(4) - Desember 2015: 233-241 (ISSN : 2303-2162)

\begin{tabular}{|c|c|c|}
\hline Pengamatan & Lokasi 1 & Lokasi 2 \\
\hline Ordo Orthoptera & 956 & 1354 \\
\hline - $\quad$ Ordo Lepidoptera & 183 & 158 \\
\hline - Ordo Odonata & 705 & 814 \\
\hline
\end{tabular}

Deskripsi lokasi

Padang rumput di tepi sebuah belik yang mengalir menuju sungai kecil. Terdapat pohon beringin dengan kanopi menutupi sebagian area penelitian. Selain itu, di tepi sungai juga digunakan oleh warga untuk menanam sayur-sayuran seperti terong dan bayam. Rumput mendominasi area kajian, terutama ilalang, teki, dan kolonjono.

Padang rumput di tepi sebuah sungai. Sungai tersebut merupakan sungai utama yang mengalir menuju air terjun Sri Gethuk. Dominasi oleh rumput-rumputan, terutama ilalang. Di beberapa bagian dari lokasi penelitian, terdapat pohon-pohon Jati dan semak-semak dari jenis Lantana camara. Ditemukan pula tanaman yang ditanam warga berupa ketela pohon dan kolonjono.

Tabel 2 menunjukkan bahwa jumlah spesies yang ditemukan di lokasi 1 dan lokasi 2 tidak berbeda jauh, berkisar antara 14 sampai 17 spesies. Namun, jika dilihat dari jumlah yang diperoleh, maka Ordo Orthoptera dapat dikatakan paling banyak, dengan 956 individu di lokasi 1 dan 1354 individu di lokasi 2. Sementara itu, Ordo Lepidoptera termasuk tidak melimpah jika dibandingkan dengan dua ordo yang lain, yaitu hanya 183 individu (Lokasi 1) dan 158 individu (Lokasi 2).Hal ini konsisten dengan deskripsi lokasi penelitian yang tidak banyak ditumbuhi oleh tanaman berbunga sebagai feeding ground dari Ordo Lepidoptera.

Hasil pengamatan dari dua lokasi penelitian adalah ditemukannya 17 spesies anggota Ordo Orthoptera, 17 species anggota Ordo Lepidoptera, dan 17 anggota Ordo Odonata. Species serangga yang ditemukan, kerapatan, indeks keragaman dan persebaran pada dua lokasi disajikan di tabel 3 berikut.

Tabel 3. Kerapatan, Indeks Keragaman, dan Persebaran species anggota Ordo Orthoptera, Lepidoptera, dan Odonata dari Kedung Poh (Lokasi 1) dan Sungai Oyo (Lokasi 2)

\begin{tabular}{|c|c|c|c|c|c|c|c|c|c|}
\hline \multirow{2}{*}{ No } & \multirow{2}{*}{ Spesies } & \multicolumn{2}{|c|}{$\begin{array}{l}\text { Jumlah } \\
\text { individu }\end{array}$} & \multicolumn{2}{|c|}{$\begin{array}{l}\text { Kerapatan } \\
(/ \mathrm{m} 2)\end{array}$} & \multicolumn{2}{|c|}{$\begin{array}{c}\text { Indeks } \\
\text { Keragaman }\end{array}$} & \multicolumn{2}{|c|}{ Persebaran } \\
\hline & & $\begin{array}{l}\text { Loka- } \\
\text { si } 1\end{array}$ & $\begin{array}{l}\text { Loka- } \\
\text { si } 2\end{array}$ & $\begin{array}{l}\text { Loka- } \\
\text { si } 1\end{array}$ & $\begin{array}{l}\text { Loka- } \\
\text { si } 2\end{array}$ & $\begin{array}{l}\text { Loka- } \\
\text { si } 1\end{array}$ & $\begin{array}{l}\text { Loka- } \\
\text { si } 2\end{array}$ & Lokasi 1 & Lokasi 2 \\
\hline \multicolumn{10}{|c|}{ Ordo Orthoptera } \\
\hline 1 & Phlaeoba fumosa & 381 & 445 & 0,381 & 0,445 & \multirow{12}{*}{0,722} & \multirow{12}{*}{0,855} & \multirow{12}{*}{$\begin{array}{c}2,47 \\
\text { Mengelom- } \\
\text { pok }\end{array}$} & \multirow{12}{*}{$\begin{array}{c}2,48 \\
\text { Mengelom- } \\
\text { pok }\end{array}$} \\
\hline 2 & Phlaeoba infumata & 272 & 351 & 0,272 & 0,351 & & & & \\
\hline 3 & Trilophidia annulata & 43 & 121 & 0,043 & 0,121 & & & & \\
\hline 4 & Oxya sinensis & 53 & 129 & 0,053 & 0,129 & & & & \\
\hline 5 & Oxya japonica & 18 & 40 & 0,018 & 0,04 & & & & \\
\hline 6 & Caryanda spuria & 10 & 7 & 0,01 & 0,007 & & & & \\
\hline 7 & $\begin{array}{l}\text { Atractomorpha } \\
\text { crenulata }\end{array}$ & 41 & 65 & 0,041 & 0,065 & & & & \\
\hline 8 & Acrida cinerea & 13 & 41 & 0,013 & 0,041 & & & & \\
\hline 9 & Conocephalus sp & 7 & 12 & 0,007 & 0,012 & & & & \\
\hline 10 & Caedicia simplex & 4 & 0 & 0,004 & 0 & & & & \\
\hline 11 & Phaneroptera falcata & 3 & 0 & 0,003 & 0 & & & & \\
\hline 12 & Locusta migratoria & 26 & 14 & 0,026 & 0,014 & & & & \\
\hline
\end{tabular}


Jurnal Biologi Universitas Andalas (J. Bio. UA.)

4(4) - Desember 2015: 233-241 (ISSN : 2303-2162)

\begin{tabular}{|c|c|c|c|c|c|c|c|c|c|}
\hline 13 & Valanga nigricornis & 9 & 10 & 0,009 & 0,01 & & & & \\
\hline 14 & Dissosteira carolina & 19 & 35 & 0,019 & 0,035 & & & & \\
\hline 15 & Gryllus sp & 51 & 65 & 0,051 & 0,065 & & & & \\
\hline 16 & Teleogryllus mitratus & 6 & 2 & 0,006 & 0,002 & & & & \\
\hline 17 & Tetrix $s p$ & 0 & 17 & 0 & 0,017 & & & & \\
\hline \multicolumn{10}{|c|}{ Ordo Lepidoptera } \\
\hline 1 & Appias lyncida & 3 & 5 & 0,003 & 0,005 & \multirow{17}{*}{0,99} & \multirow{17}{*}{0,81} & \multirow{17}{*}{$\begin{array}{c}1,7 \\
\text { Mengelom- } \\
\text { pok }\end{array}$} & \multirow{17}{*}{$\begin{array}{c}1,28 \\
\text { Mengelom } \\
\text { pok }\end{array}$} \\
\hline 2 & Appias olferna & 0 & 2 & 0 & 0,002 & & & & \\
\hline 3 & Catopsilia pomona & 31 & 46 & 0,031 & 0,046 & & & & \\
\hline 4 & Eurema blanda & 7 & 3 & 0,007 & 0,003 & & & & \\
\hline 5 & Acraea violae & 0 & 3 & 0 & 0,003 & & & & \\
\hline 6 & Danaus chrysippus & 14 & 7 & 0,014 & 0,007 & & & & \\
\hline 7 & Hypolimnas bolina & 2 & 1 & 0,002 & 0,001 & & & & \\
\hline 8 & Junonia almana & 9 & 3 & 0,009 & 0,003 & & & & \\
\hline 9 & Junonia atlites & 46 & 1 & 0,046 & 0,001 & & & & \\
\hline 10 & Junonia orithya & 6 & 1 & 0,006 & 0,001 & & & & \\
\hline 11 & Mycalesis mineus & 2 & 1 & 0,002 & 0,001 & & & & \\
\hline 12 & Phalanta phalanta & 8 & 33 & 0,008 & 0,033 & & & & \\
\hline 13 & Yoma sabina & 0 & 1 & 0 & 0,001 & & & & \\
\hline 14 & Chilades pandava & 10 & 4 & 0,01 & 0,004 & & & & \\
\hline 15 & Zizina otis & 25 & 27 & 0,025 & 0,027 & & & & \\
\hline 16 & Zizula hylax & 8 & 18 & 0,008 & 0,018 & & & & \\
\hline 17 & Taractrocera archias & 12 & 2 & 0,012 & 0,002 & & & & \\
\hline \multicolumn{10}{|c|}{ Ordo Odonata } \\
\hline 1 & Orthetrum sabina & 252 & 188 & 0,252 & 0,188 & \multirow{17}{*}{0,79} & \multirow{17}{*}{0,85} & \multirow{17}{*}{$\begin{array}{c}1,17 \\
\text { Mengelom- } \\
\text { pok }\end{array}$} & \multirow{17}{*}{$\begin{array}{c}2,01 \\
\text { Mengelom- } \\
\text { pok }\end{array}$} \\
\hline 2 & Pseudagrion rubriceps & 66 & 289 & 0,066 & 0,289 & & & & \\
\hline 3 & Ischnura senegalensis & 1 & 74 & 0,001 & 0,074 & & & & \\
\hline 4 & Trithemis aurora & 176 & 58 & 0,176 & 0,058 & & & & \\
\hline 5 & Pantala flavencens & 10 & 37 & 0,01 & 0,037 & & & & \\
\hline 6 & Libellago lineata & 33 & 39 & 0,033 & 0,039 & & & & \\
\hline 7 & Copera marginipes & 8 & 4 & 0,008 & 0,004 & & & & \\
\hline 8 & $\begin{array}{l}\text { Brachytemis } \\
\text { contaminata }\end{array}$ & 23 & 38 & 0,023 & 0,038 & & & & \\
\hline 9 & Crocothemis servilia & 106 & 0 & 0,106 & 0 & & & & \\
\hline 10 & Rhynocypa fenestrata & 1 & 9 & 0,001 & 0,009 & & & & \\
\hline 11 & Diplacodes trivialis & 6 & 45 & 0,006 & 0,045 & & & & \\
\hline 12 & $\begin{array}{l}\text { Prodasineura } \\
\text { autumnalis }\end{array}$ & 2 & 13 & 0,002 & 0,013 & & & & \\
\hline 13 & Neurothemis terminata & 7 & 4 & 0,007 & 0,004 & & & & \\
\hline 14 & $\begin{array}{l}\text { Ictinogomphus } \\
\text { decoratus }\end{array}$ & 6 & 8 & 0,006 & 0,008 & & & & \\
\hline 15 & $\begin{array}{l}\text { Paragomphus } \\
\text { reinwardtii }\end{array}$ & 4 & 8 & 0,004 & 0,008 & & & & \\
\hline 16 & Potamarcha congener & 2 & 188 & 0,002 & 0,188 & & & & \\
\hline 17 & Agriocnemis femina & 2 & 289 & 0,002 & 0,289 & & & & \\
\hline
\end{tabular}


Anggota ordo Orthoptera yang paling banyak ditemukan pada 2 lokasi adalah Phlaeoba fumosadengan jumlah individu sebanyak 381 di lokasi 1 (kerapatan 0,381 individu/ m2) dan 445 individu (kerapatan $0,445 \mathrm{individu} / \mathrm{m} 2$ ) di lokasi 2.Jumlah individu tersebut diikuti oleh Phlaeoba infumata dengan jumlah individu 272 (kerapatan 0,272 individu/m2) di lokasi 1 dan $351 \quad(0,351$ individu/m2) di lokasi 2. Genus Phlaeoba dikenal sebagai short-horned grasshopper atau serangga dengan 'tanduk' yang berukuran pendek. Serangga ini hidup secara terestrial dan diidentifikasi sebagai hama sayuran dan tanaman pangan (Mandal et al., 1991). Meskipun termasuk serangga yang polifaga, ketika dibiakkan di laboratorium, Phlaeobainfumata lebih menyukai Cyperus rotundus (rumput teki) (Mandal et al, 1991). Hal ini sesuai dengan kondisi lokasi penelitian yang banyak ditumbuhi oleh rumputrumputan, termasuk teki.

Jumlah individu anggota Orthoptera yang paling sedikit ditemukan adalah species Phaneroptera falcata. Spesies ini hanya ditemukan di lokasi 1 (Kedung Poh), dengan jumlah 3 individu (kerapatan 0,003 individu/m2). Spesies ini menyukai tempat yang kering, temperatur hangat seperti padang rumput, tepi hutan, perkebunan anggur, lahan kering dan terbuka (Pygrus, n.d). Pengamatan menunjukkan, lokasi penelitian merupakan habitat yang baik bagi Phaneroptera, namun vegetasi di lokasi penelitian sangat jarang yang merupakan habitat terbuka, sehingga predator dapat dengan mudah menemukan dan melihat berbagai macam serangga yang menjadi pakannya. Salah satu jenis predator yang tampak dalam pengamatan adalah burung Lanius shach yang merupakan insektivora pemakan belalang (Lala et al., 2003).

Anggota Ordo Lepidoptera yang sering dijumpai di 2 lokasi penelitian adalah Catopsilia pomona dengan 31individu (Lokasi 1) dan 46 individu (Lokasi 2).C. pomona merupakan spesies kupu-kupu berwarna kecil, biasanya ditemukan secara berkelompok dengan kupu-kupu lain (CSIRO, 1992). Genus yang banyak ditemukan adalah Junonia, dengan tiga spesies yaitu J. almana, J. atlites, dan $J$. orithya. Serangga ini ditandai dengan adanya corak berwarna biru-hitam pada sayap belakang yang menyerupai mata (eyespot).
Diduga keberadaan eyespot berfungsi untuk mengusir predator (Valin et al., 2005 dalam Kodandaramaiah, 2009). Hal ini diduga menjadi penyebab mengapa banyak genus Junonia yang bisa ditemukan, karena mereka mampu menggunakan eyespotnya dan menghindari predator.

Sementara itu, spesies anggota Ordo Odonata yang paling banyak ditemukan adalah Orthetrum sabina, yaitu 252 individu di lokasi 1 dan 188 individu di lokasi 2.O. sabina adalah spesies yang sangat mudah berkembang biak dan tersebar dengan sangat luas di bagian timur Indonesia (Watson, 1984). Dengan kondisi ini tidak mengherankan bahwa $O$. sabina bisa ditemukan dengan mudah di kawasan Desa Bleberan, Gunung Kidul, karena meskipun daerahnya kering, kawasan pengambilan sampel masih memiliki sumber air sebagai tempat untuk bertelur dan hidupnya nimfa capung. Selain di Indonesia timur, $O$. sabina juga umum ditemukan di Borneo (Samsudin, 2013). Kelimpahan ini diikuti oleh Pseudagrion rubriceps dengan 66 individu (Lokasi 1) dan 289 individu (Lokasi 2),sedangkan spesies Crocothemis servilia hanya ditemukan di lokasi 1 dengan 106 individu.

Data indeks keragaman berkisar antara 0,79 sampai dengan 0,99. Hal ini menunjukkan bahwa ekosistem yang dikaji berada pada kondisi keanekaragaman rendah, produktivitas sangat rendah sebagai indikasi adanya tekanan yang berat dan ekosistem tidak stabil (Krebs, 1978).Hal ini sesuai dengan Lee et al. (1975) dalam Wardhana (1995) yang menyatakan bahwa suatu ekosistem yang memiliki indeks keragaman < 1 maka ekosistem tersebut tercemar berat. Sedangkan menurut Fahrul (2007), apabila indeks keragaman berkisar antara 1 sampai 3 maka kondisi ekosistem stabil dan apabila indeks keragaman kurang dari $1 \quad\left(H^{\prime}<1\right)$ maka ekosistem tidak stabil. Keanekaragaman tertinggi terdapat pada Ordo Lepidoptera di Lokasi 1. Hal ini terjadi karena keberadaan vegetasi yang lebih beragam di Lokasi 1, dimana sebagaian area dari Lokasi 1 adalah area pertanian dengan tanaman-tanaman yang mengandung nektar seperti terong dan kacangkacangan. Selain faktor keragaman, data lain yang diambil dari penelitian ini adalah data faktor lingkungan berupa suhu udara, 
Jurnal Biologi Universitas Andalas (J. Bio. UA.)

4(4) - Desember 2015: 233-241 (ISSN : 2303-2162)

kelembaban udara, dan intensitas cahaya (tabel

4).

Tabel 4. Pengukuran Parameter Suhu, Kelembaban, dan Intensitas Cahaya di Kedung Poh (Lokasi 1) dan Sungai Oyo (Lokasi 2)

\begin{tabular}{ccccccc}
\hline \multirow{2}{*}{ Titik } & \multicolumn{2}{c}{ Suhu (oC) } & \multicolumn{2}{c}{ Kelembaban (\%) } & \multicolumn{2}{c}{ Cahaya (x100 lux) } \\
\cline { 2 - 7 } & Lokasi 1 & Lokasi 2 & Lokasi 1 & Lokasi 2 & Lokasi 1 & Lokasi 2 \\
\hline 1 & 28,8 & 28 & 59 & 64,25 & 566,4 & 106 \\
\hline 2 & 29,8 & 29,25 & 55,8 & 61,25 & 726,6 & 162,5 \\
\hline 3 & 28,8 & 32,25 & 58,2 & 54,25 & 326,8 & 220 \\
\hline 4 & 32,6 & 33,25 & 43,2 & 48,75 & 632,8 & 354,5 \\
\hline 5 & 32,4 & 33 & 46,4 & 47 & 477,4 & 116 \\
\hline 6 & 32,6 & 34 & 46,4 & 42 & 664,4 & 215,5 \\
\hline 7 & 32,4 & 32,5 & 45,4 & 44,5 & 561 & 359 \\
\hline 8 & 32 & 34,75 & 45,8 & 44,75 & 431,8 & 200 \\
\hline 9 & 31,6 & 34,75 & 45,8 & 44,25 & 450,8 & 403,5 \\
\hline 10 & 31,8 & 34,5 & 54,2 & 44,75 & 220,4 & 400,5 \\
\hline rata-rata & 31,28 & 32,625 & 50,02 & 49,575 & 505,84 & 253,75 \\
\hline
\end{tabular}

Tabel 4 merangkum semua pengukuran faktor abiotik pada lokasi penelitian. Pengukuran terhadap suhu menunjukkan rata-rata suhu di Lokasi 1 yaitu $31,28{ }^{\circ} \mathrm{C}$ dan di lokasi 2 yaitu $32,625{ }^{\circ} \mathrm{C}$. Kisaran suhu ini termasuk suhu normal yang dapat mendukung kehidupan serangga (Gillot, 2005). Demikian pula, hasil pengukuran kelembaban udara menunjukkan kisaran antara $43,2 \%$ sampai $64,25 \%$, dengan kelembaban

\section{Kesimpulan}

Ditemukan masing-masing 17 spesies anggota Ordo Orthoptera, Ordo Lepidoptera dan Ordo Odonata di Lokasi 1 (Kedung Poh) dan Lokasi 2 (Sungai Oyo). Spesies yang paling melimpah dari Ordo Orthoptera yaitu Phlaeoba fumosa, Ordo Lepidoptera yaituCatopsilia pomona, dan Ordo Odonata yaitu Orthetrum sabina. Indeks keragaman semua stasiun nilainya kurang dari $1\left(H^{\prime}<1\right)$ artinya ekosistem dalam keadaan tidak stabil, terdapat ancaman terhadap keragaman Gastropoda. Terdapat satu kategori persebaran (distribusi) serangga di lokasi peneltian yaitu mengelompok dan seragam. Faktor lingkungan kimia dan fisika yang terukur menunjukkan kisaran ideal bagi kehidupan serangga. rata-rata di lokasi 1 sebesar 50,02\% dan di lokasi 2 sebesar 49,575 \%. Meskipun tergolong memiliki kelembaban udara yang rendah, kelembaban udara ini masih mampu mendukung kehidupan serangga (Borror et al., 1992), sedangkan parameter intensitas cahaya rata-rata 505,84 x 100 lux (Lokasi 1) dan 253, 75 x 100 lux (Lokasi 2).

\section{Ucapan Terima Kasih}

Ucapan terimakasih disampaikan kepada Lembaga Penelitian dan Pengabdian Pada Masyarakat (LP2M) UIN Sunan Kalijaga Yogyakarta atas bantuan dana yang diberikan sehingga penelitian ini dapat terlaksana. Peneliti juga menyampaikan terimakasih kepada tim pengambil data yaitu Fuzna Sumi Untari, Dis Setia dan Urwatul Wustqo

\section{Daftar Pustaka}

Alford, D. 1999. Agricultural Entomology. UK: Blackwell

Balai Besar Wilayah Sungai. n.d. Wilayah Kerja Bbws Serayu Opak. Diunduh tanggal 11 November dari http://bbwsso.net/sisda/wilayah_kerja.html 
Balai Pengelolaan Daerah Aliran Sungai Serayu Opak Progo. 2009. Diunduh 2 November 2014 dari http://bpdasserayuopakprogo.dephut.go.id/kegiatan/ perencanaan/luas-das

Borror, D.J., Triplehorn, C.A., and Johnson, N.F. 1992. An Introduction to Study of Insect, 6th ed. Sanders College Publication

Byrd, J.H. \& Castner, J.L. 2002. Forensic Entomology: The Utility of Arthropods in Legal Investigation. Washington: CRC Press

CSIRO, 1991. The Insects of Austalia. Division of Commonwealth Scientific and Industrial Research Organisation.

David, A. Fennell, P., Eagles, F.J. 1990. Ecotourism in Costa Rica: A Conceptual Framework. Journal of Park and Recreation Administration (8):1

Fachrul, M..F. 2007.Metode Sampling Bioekologi, Jakarta: Rineka Cipta

Gillot, C. 2005. Entomology. 3rd ed. Canada: Springer

Gunung Kidul Online. 2013. Inilah 15 Desa Wisata di Kabupaten Gunungkidul. Diunduh 2 November 2014 dari http://gunungkidulonline.com/inilah-15desa-wisata-di-kabupaten-gunungkidul/

Jianxiong Qin, J., Zhang, P., Deng, G., Chen, L. 2014. A Study on Eco-Tourism and SustainableDevelopment of EconomicUnderdevelopment AreasAn Examplefrom Kanas Nature Reserve, XingjiangProvince, Northwest China. Smart Grid and Renewable Energy (5):170-179

Kiper, T. 2013. Role of Ecotourism in Sustanable Development. Dalam Özyavuz, M. Advances in Landscape Architecture. Buku online diunduh tanggal 12 November 2014 dari http://www.intechopen.com/books/adva nces-in-landscape-architecture/role-ofecotourism-in-sustainable-development ISBN 978-953-51-1167-2
Kodandaramaiah, U. 2009. Eyespot Evolution: Phylogenetic Insights From Junonia And Related Butterfly Genera (Nymphalidae: Junoniini). Evolution \& Development 11:5, 489-497

Krebs, C.J. 1978. Ecology: The Experimental Analysis of Distribution and Abundance. New York: Harper and Row Publishers.

Lala, F., Wagiman, F.X., Putra, N.S. 2003. Keanekaragaman Serangga dan Struktur Vegetasi pada Habitat burung Insektivora Lanius schach Linn. di Tanjungsari, Yogyakarta. Jurnal Entomologi Indonesia (10): 2, p 70-77

Mandal, S.K., Hazra, A.K., Tandon, S.K. 1992. On The Biology and The Nymphal Taxonomy of Phaleoba infumata Brunner (Acrididae) Under Lab Condition. Rec. Zool. Surv. (91):1, p. $35-48$

Pemerintah Daerah Gunung Kidul, n.d.diunduh tanggal 11 Oktober 2014 darihttp://gunungkidulkab.go.id/home.p hp?mode $=$ content $\& \mathrm{id}=121$

Pygrus (n.d). Phaneroptera falcata. Diunduh tanggal 24 November 2015 dari http://www.pyrgus.de/Phaneroptera falc ata_en.html

Restu, I.W. 2002. Kajian Pengembangan Wisata Mangrove di Taman Hutan Raya Ngurah Rai Wilayah Pesisir Selatan Bali. [Tesis]. Bogor: Program Pasca Sarjana, Institut Pertanian Bogor.

Rohman, A. 2012. Keanekaragaman Jenis Dan Distribusi Capung(Odonata)Dikawasan Kars Gunung Sewu KecamatanPracimantoro, Kabupaten Wonogiri, Jawa Tengah. Skripsi. PMIPA, Universitas Negeri Yogyakarta

Samsudin, N. 2013. Morphological Variation of Selected Species in the Genus of $O$. sabina (Odonata: Anisoptera) in Sarawak. Bachelor of Science Thesis. University Malaysia Sarawak.

Speight, M.R., Hunter, M.D., Watt, A.D., 1999. Ecology of Insects, Concepts and 
Jurnal Biologi Universitas Andalas (J. Bio. UA.)

4(4) - Desember 2015: 233-241 (ISSN : 2303-2162)

Applications.Blackwell Science,Ltd.

$169-179$

Van Swaay, C.A.M., Brereton, T., Kirkland, P. and Warren, M.S. (2012) Manual for Butterfly Monitoring. Report VS2012.010, De Vlinderstichting/Dutch Butterfly Conservation, Butterfly Conservation UK \& Butterfly Conservation Europe, Wageningen.

Trisnawati, D. 2009. Analisis Indeks Geomorfik Dalam Menentukan Pengaruh Tektonik Pada Sub Daerah Aliran Sungai Oyo. Universitas Diponegoro. Diunduh 11 November 2014

dari http://eprints.undip.ac.id/20994/1/Devin a T.pdf

Wardhana, W.A., 1995, Dampak Pencemaran Lingkungan, Yogyakarta: Andi Offset

Watson, J.A.L., 1984. A Second Australian Species in the Orthethrum sabina Complex (Odonata: Libellulidae). $J$. Aust. Ent. Soc 23: 1-10 